\title{
Assessment of the Facial Profile: The Correlation between Various Cephalometric Analyses and the Soft Tissue Angle of Convexity
}

\author{
Maheen Ahmed $^{1}$ BDS \\ Attiya Shaikh ${ }^{2}$ \\ Mubassar Fida $^{3}$
BDS, FCPS(Ortho), FDS RCSEd (UK), MOrth RCSEd (UK)
BDS, MCPS \& FCPS (Orthodontics), MCPS (Periodontology), MCPS (Community Dentistry), PGD HIMS

\begin{abstract}
:
Introduction: The study was designed to identify skeletal analyses that best correlate with the parameter used to assess facial soft tissue profile. This may result in a soft tissue oriented approach for the diagnosis of the underlying sagittal skeletal discrepancy, which may subsequently lead to the development of a treatment plan that may give better soft tissue outcome.

Methodology: A sample of 198 subjects (99 males and 99 females; mean age $=23.6 \pm 4.6$ years) was uniformly divided into Class I, II and III sagittal groups on the basis of soft tissue angle of convexity. Various sagittal parameters including ANB angle, AB plane angle, Downs angle of convexity, Wits appraisal, Beta angle and W angle were assessed on pretreatment lateral cephalograms. Correlation between various skeletal analyses and the soft tissue angle of convexity was determined using Spearman's correlation.

Results: The ANB angle showed the highest correlation with the soft tissue angle of convexity ( $\mathrm{r}=0.907)$, whereas W angle showed the least correlation $(\mathrm{r}=0.744)$. Amongst the sagittal groups, no significant correlation was present in Class I group. Downs angle of convexity showed a moderate positive correlation in Class II $(r=0.514)$ and Class III ( $\mathrm{r}=0.533$ ) sagittal groups with the soft tissue parameter.

Conclusion: ANB angle and Downs angle of convexity were found to be reliable skeletal indicators in assessing the facial soft tissue profile. Hence, the number of cephalometric analyses for evaluating the sagittal skeletal jaw discrepancy may be limited to fewer analyses of higher diagnostic performance, which are more reliably related to the overlying facial pattern.

KEYWORDS: Soft tissue, Cephalometry, Sagittal dimension.

HOW TO CITE: Ahmed M, Shaikh A, Fida M. Assessment of the Facial Profile: The Correlation between Various Cephalometric Analyses and the Soft Tissue Angle of Convexity. J Pak Dent Assoc 2017; 26(2): 59-66.
\end{abstract}

Received: 10 February 2017, Accepted: 9 June 2017

\section{INTRODUCTION}

$\mathrm{T}$ The perception of facial esthetics varies according to the genetic, age, gender, cultural norms and environmental factors ${ }^{1}$. Despite variations in

1. Resident Orthodontics, Section of Dentistry, Department of Surgery, The Aga Khan University Hospital, Karachi, Pakistan

2. Assistant Professor, Liaquat College of Medicine and Dentistry, Karachi, Pakistan

3. Consultant Orthodontist/Associate Professor, Program Director Orthodontics Residency Program, Section of Dentistry, Department of Surgery, The Aga Khan University Hospital, Karachi, Pakistan

Corresponding author: "Dr. Maheen Ahmed"

<a_maheen01@hotmail.com> standards, people tend to prefer faces that are balanced ${ }^{2}$. Hence for adequate esthetics, a face should be proportionate in all three dimensions i.e. sagittal, vertical and transverse. Variations in growth are common and may have certain clinical implications. A variation in sagittal growth may result in a convex or a concave profile. It can be either due to discrepancy in hard or soft tissues that form the face. A sagittal maxillary excess or mandibular deficiency may result in a convex profile with excessive overjet, and incompetent lips. In contrast, a sagittal maxillary deficiency or mandibular excess may lead to a prognathic profile and an anterior crossbite. 
After standardization of the cephalogram by Broadbent ${ }^{3}$, skeletal analysis was preferred over soft tissue facial profile as treatment planning during that era was dictated by the Angle's paradigm ${ }^{4}$. However, the relationship between the facial profile and the underlying skeletal structures was found to be inconsistent in different sagittal facial patterns ${ }^{5}$. Additionally ,utilization of only skeletal parameters may result in unesthetic soft tissue appearance ${ }^{6}$. Therefore, currently the process of treatment planning now aims at achieving adequate facial esthetics and a functional occlusion ${ }^{7}$.

The assessment of anteroposterior skeletal discrepancy has been made simpler with the introduction of lateral cephalometry. Various analyses have also been proposed for diagnosing the sagittal discrepancies. Downs ${ }^{8}$ described the $\mathrm{AB}$ plane angle, as a mean to assess the antero-posterior dysplasia followed by the Downs angle of convexity. In 1953, Riedel ${ }^{9}$ introduced the famous ANB angle which was popularized by Steiner ${ }^{10}$. Studies have indicated that the ANB angle varies with position of Nasion and vertical growth pattern ${ }^{11,12}$. To overcome this, Jacobson ${ }^{12}$ proposed the Wits appraisal using the occlusal plane as the reference plane. Later the Wits appraisal was deemed unreliable due to variations in the occlusal plane ${ }^{13}$. Hence, several parameters have been and are still being introduced to overcome the shortcomings of existing parameters for accurate diagnosis of sagittal discrepancies. Recently Beta angle and $\mathrm{W}$ angle have been proposed to measure the antero-posterior jaw dysplasia $^{14,15}$. Apart from the errors in the landmark identification, variations may occur due to racial and ethnic differences ${ }^{16}$.

The goals of an orthodontic treatment are established by the soft tissues that form the face ${ }^{7}$. These not only determine the facial esthetics but also define the limitations of the treatment ${ }^{17}$. To date only few studies assessed the correlation of various skeletal and soft tissue parameters for the evaluation of anteroposterior facial pattern ${ }^{18-20}$. Moreover during orthodontic diagnosis, certain cases present with varied readings and a specific sagittal pattern is difficult to determine. This study aimed to identify skeletal parameters that more closely correlate with the analyses use to evaluate the facial soft tissue profile. This may lead to an accurate diagnosis and an efficient treatment plan. Moreover, a clinician may save time by the utilizing only those parameters that more closely represent the facial soft tissue pattern.

\section{METHODOLOGY}

The data was collected retrospectively from the dental records of patients visiting our clinics. Keeping $\alpha=0.05$, using the correlation value $(r)=0.119$ between Down's angle of convexity and soft tissue angle of convexity as reported by Raman et al., ${ }^{19}$ power of study $(\beta)$ was kept at 90 $\%$. The total sample size was calculated to be 178 . This number was increased by around $10 \%$ to obtain the sample size of 198 subjects. Subjects aged 18-35 years having clear and good quality radiographs with normodivergent growth pattern were included. The sample comprised of equal number of males and females. Subjects with any growth problems, trauma or orthodontic treatment were excluded. As growth may affect the size of skeletal and soft tissue structures hence only adult subjects were included in the study $^{21}$. Further only normodivergent subjects based on FMA, SN-GoGn and PFH-TAFH were included as variations in vertical growth pattern may affect the sagittal parameters ${ }^{11}$.

The sample was equally divided into Class I, II and III groups based on soft tissue angle of convexity (G'Sn/SnPog') as follows: ${ }^{22}$

$>$ Class I: G’Sn/SnPog' $>17^{\circ}[$ Males -33 ; Females 33]

$>$ Class II: G’Sn/SnPog' $=8^{\circ}-16^{\circ}[$ Males -33 ; Females - 33]

> Class III: G'Sn/SnPog' $<7^{\circ}[$ Males -33 ; Females 33]

Cephalograms were traced manually on acetate paper with $0.5 \mathrm{~mm}$ lead pencil by the principal investigator. The specific landmarks and planes for evaluating the sagittal skeletal and soft tissue growth pattern were identified (Fig. 1). The various skeletal parameters and soft tissue angle of convexity were determined on the lateral cephalogram with the help of a millimeter ruler and protractor, respectively.

Skeletal Parameters: (Figs. 2 and 3)

1. ANB Angle: The angle formed by point A, Nasion and point $\mathrm{B}$ (normal range $=0^{\circ}$ to $\left.4^{\circ}\right)^{10}$

2. Wits Appraisal: The linear distance between $\mathrm{AO}$ and $\mathrm{BO}$ (perpendicular drawn from point $\mathrm{A}$ and $\mathrm{B}$ on to functional occlusal plane) (normal range $=-1 \mathrm{~mm}$ to $+1 \mathrm{~mm})^{12}$

3. AB plane Angle: The angle formed by $\mathrm{AB}$ plane and Npog line (normal range $=9^{\circ}$ to $\left.0^{\circ}\right)^{8}$

4. Beta Angle: The angle formed by $\mathrm{A}-\mathrm{CB}$ and $\mathrm{AB}$ line (normal range $=27^{\circ}$ to $\left.35^{\circ}\right)^{14}$

5. W Angle: The angle between the perpendicular line from point $\mathrm{M}$ to $\mathrm{S}-\mathrm{G}$ line and the $\mathrm{M}-\mathrm{G}$ line (normal range = $51^{\circ}$ to $\left.55^{\circ}\right)^{15}$

6. Downs angle of convexity: The angle between N-point A and point A-Pog (normal range $=-8.5^{\circ}$ to $\left.10^{\circ}\right)^{8}$ 


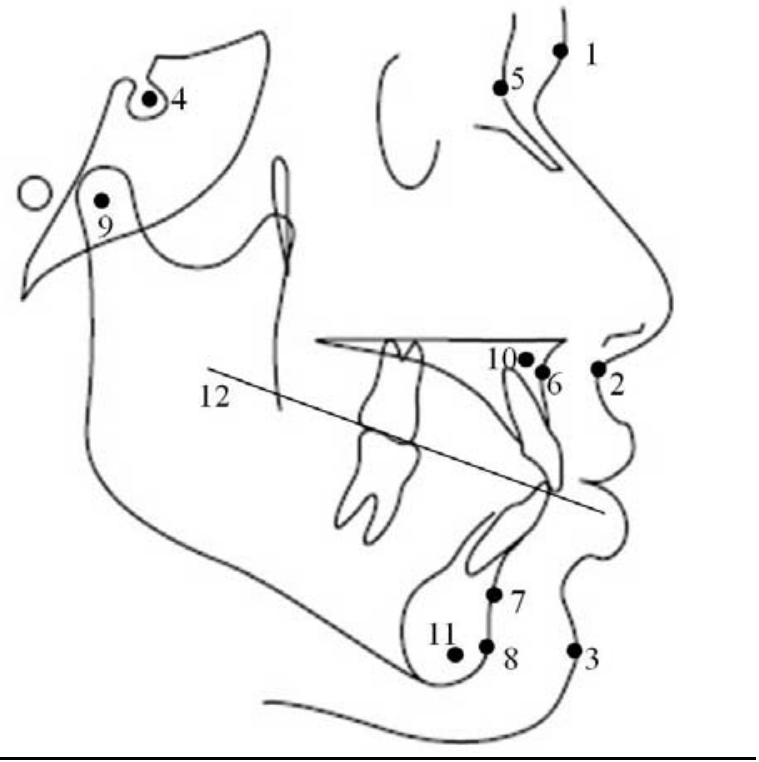

Fig. (1). Cephalometric landmarks and the occlusal plane.

1. Soft tissue glabella (G'): The most anterior point in midsagittal plane of the forehead

2. Subnasale (Sn): The point at which the columella merges with upper lip

3. Soft tissue pogonion (Pog'): The most anterior point on the soft tissue chin

4. Sella (S): The center of sella turcia cavity

5. Hard tissue nasion(N): The most anterior point on the frontonasal suture

6. A-point (A): The deepest point on the concavity at the anterior surface of the maxilla

7. B-point (B): The deepest point on the concavity at the anterior surface of the mandibular symphysis

8. Hard Tissue pogonion(Pog): The most anterior point on bony chin

9. Condylion(C): The center of the condyler head of the mandible

10. M-point (M): The center of premaxilla

11. G-point (G): The center of mandibular symphysis

12. Occlusal Plane(OP): The maximum intercuspation of posterior teeth

Soft tissue angle of convexity: The angle formed by G'-Sn and Sn-Pog' (normal range $=8^{\circ}$ to $\left.16^{\circ}\right)^{22}$ (Fig. 3)

To rule out the measurement error, thirty cephalograms were randomly selected, retraced and remeasured by the principal investigator to assess the intra-examiner reliability. The results showed a high correlation (Table $\mathbf{1}$ ).

Data were analyzed using SPSS for Windows (version 20.0, SPSS Inc. Chicago). Baseline information on demographics was analyzed using descriptive statistics. A Shapiro Wilk test was performed for all the variables which indicated a non-normal distribution of the data. A MannWhitney $U$ test was performed to check for gender dimorphism. A Kruskal Wallis test was used to compare the age among the three sagittal groups. To evaluate the skeletal parameter that best conformed to the soft tissue facial profile, the correlation of various sagittal skeletal analyses with the soft tissue angle of convexity was determined using the Spearman's correlation. A p-value of $\leq 0.05$ was taken as statistically significant.

\section{RESULTS}

The means of each parameter between genders were compared using Mann-Whitney $U$ test. The results showed no statistically significant difference between the two groups (Table 2). The mean age amongst the three sagittal groups was compared using the Kruskal Wallis test. The results showed insignificant differences (Table 3).

Spearman's correlation showed a significant correlation between skeletal parameters and the soft tissue angle of convexity. Amongst the skeletal parameters, ANB angle showed the highest correlation with the soft tissue angle of convexity $(\mathrm{r}=0.907, \mathrm{p}<0.01)$ (Table 4$)$. 


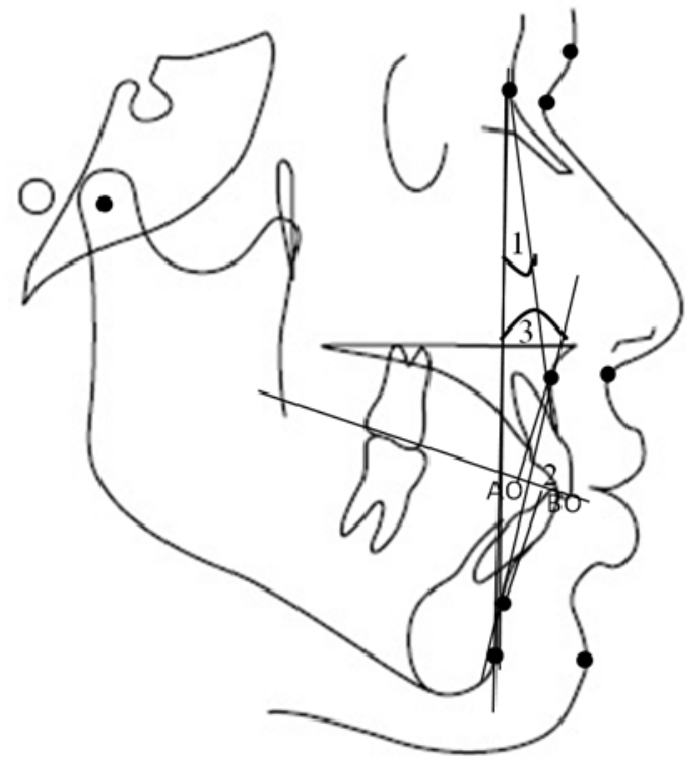

Fig. (2). Cephalometric parameters.

1. ANB angle: The angle formed by point $A$, nasion and point $B$ (normal range $=0^{\circ}$ to $4^{\circ}$ )

2. Wits appraisal: The linear distance between $\mathrm{AO}$ and $\mathrm{BO}$ (perpendicular drawn from point $\mathrm{A}$ and $\mathrm{B}$ on to functional occlusal plane) (normal range $=-1 \mathrm{~mm}$ to $+1 \mathrm{~mm}$ )

3. AB plane angle: The angle formed by $\mathrm{AB}$ plane and $\mathrm{N}$-pog line (normal range $=9^{\circ}$ to $0^{\circ}$ )

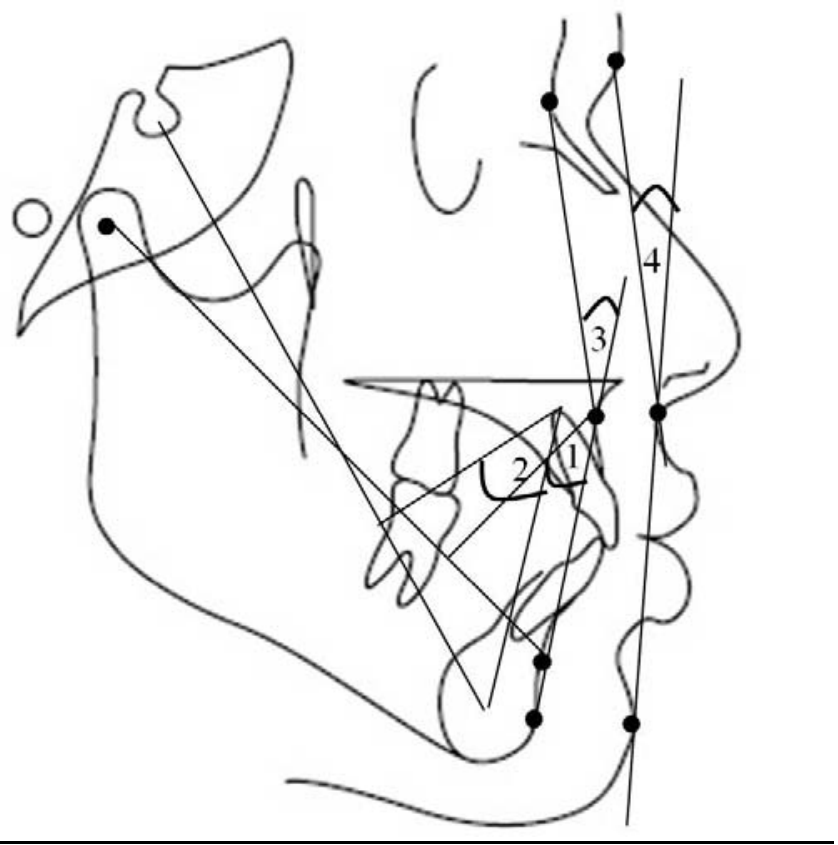

Fig. (3). Cephalometric parameters.

1. Beta angle: The angle formed by $\mathrm{A}-\mathrm{CB}$ and $\mathrm{AB}$ line (normal range $=27^{\circ}$ to $35^{\circ}$ )

2. W angle: The angle between the perpendicular line from point $M$ to $S-G$ line and the $M-G$ line (normal range $=51^{\circ}$ to $55^{\circ}$ )

3. Downs angle of convexity: The angle between N-point A and point A-Pog (normal range $=-8.5^{\circ}$ to $10^{\circ}$ )

4. Soft tissue angle of convexity: The angle formed by G'-Sn and Sn-Pog' (normal range $=8^{\circ}$ to $16^{\circ}$ ) 
Table 1. Assessment of Measurement Error

\begin{tabular}{|c|c|c|c|}
\hline Measurements & $\begin{array}{c}\mathbf{1}^{\text {st }} \text { Reading } \\
(\mathbf{n}=\mathbf{3 0})\end{array}$ & $\begin{array}{c}\mathbf{2}^{\text {nd }} \text { Reading } \\
\text { (n=30) }\end{array}$ \\
\hline \hline ANB angle (degree) & $1.67 \pm 4.81$ & $1.87 \pm 4.96$ & 0.997 \\
\hline Wits appraisal (mm) & $-1.48 \pm 5.46$ & $-1.48 \pm 5.59$ & 0.997 \\
\hline Beta angle (degree) & $34.13 \pm 8.82$ & $34.40 \pm 8.92$ & $-2.87 \pm 7.93$ \\
\hline AB plane angle (degree) & $-2.80 \pm 7.76$ & $1.67 \pm 10.38$ & 0.995 \\
\hline Downs angle of convexity (degree) & $1.63 \pm 10.29$ & $54.67 \pm 5.97$ \\
\hline W angle (degree) & $54.40 \pm 5.82$ & $11.03 \pm 10.54$ & 0.992 \\
\hline Soft tissue angle of convexity (degree) & $10.93 \pm 10.50$ & 0.993 \\
\hline
\end{tabular}

ICC: Intraclass Correlation Coefficient.

Table 2. Comparison of Means and Standard Deviations of Different Parameters between Males and Females

\begin{tabular}{|c|c|c|c|}
\hline Parameter & Male (n=99) & Female (n=99) \\
(mean \pm SD) & (mean \pm SD)
\end{tabular}

$\mathrm{N}=198 ; \mathrm{SD}-$ Standard Deviation

${ }^{*} \mathrm{p}<0.05 ; * * \mathrm{p}<0.01$

Mann - Whitney U test

Table 3. Comparison of Mean Age Amongst the Three Sagittal Groups

\begin{tabular}{|c|c|c|c|}
\hline Sagittal Facial Pattern & N & $\begin{array}{c}\text { Mean age } \\
\text { (years } \pm \text { SD) }\end{array}$ \\
\hline \hline Class I & 66 & $21.01 \pm 5.76$ \\
\hline Class II & 66 & $20.93 \pm 5.99$ \\
\hline Class III & 66 & $21.91 \pm 6.71$ \\
\hline Total & 198 & $21.28 \pm 6.15$ \\
\hline
\end{tabular}

$\mathrm{N}=198 ; \mathrm{SD}-$ Standard Deviation

$\mathrm{p}<0.05$; Kruskal Wallis test 
Table 4. Correlation of Skeletal Analyses to Soft Tissue Angle of Convexity

\begin{tabular}{|c|c|c|}
\hline Parameter & Correlation with the soft tissue angle of convexity & $\mathbf{p}$ \\
\hline \hline ANB angle (degree) & $0.907^{\dagger \dagger \dagger}$ & $<0.01^{* *}$ \\
\hline Wits appraisal (mm) & $0.808^{\dagger \dagger \dagger}$ & $<0.01^{* *}$ \\
\hline Beta angle (degree) & $-0.799^{\dagger \dagger}$ & $<0.01^{* *}$ \\
\hline AB plane angle (degree) & $-0.853^{\dagger \dagger}$ & $<0.01^{* *}$ \\
\hline Downs angle of convexity (degree) & $0.874^{\dagger \dagger \dagger}$ & $<0.01^{* *}$ \\
\hline W angle (degree) & $0.744^{\dagger \dagger}$ & $<0.01^{* *}$ \\
\hline
\end{tabular}

$\mathrm{N}=198$; Spearman's Correlation; correlation $=\mathrm{r}$

${ }^{\dagger}$ Weak Correlation $( \pm 0.01<r< \pm 0.5) ;{ }^{\dagger \dagger}$ Moderate Correlation $( \pm 0.5<r< \pm 0.8) ;{ }^{\dagger \dagger}$ Strong Correlation $( \pm 0.8<r< \pm 1) * \mathrm{p}<0.05 ; * * \mathrm{p}<0.01$

Table 5. Correlation of Skeletal Analyses to Soft Tissue Angle of Convexity in Class I, II and III Sagittal Groups

\begin{tabular}{|c|c|c|c|c|c|c|}
\hline \multirow[t]{2}{*}{ Parameter } & \multicolumn{2}{|c|}{$\begin{array}{l}\text { Class I } \\
n=66\end{array}$} & \multicolumn{2}{|c|}{$\begin{array}{l}\text { Class II } \\
\mathbf{n}=66\end{array}$} & \multicolumn{2}{|c|}{$\begin{array}{l}\text { Class III } \\
n=66\end{array}$} \\
\hline & $\mathbf{r}$ & $\mathbf{p}$ & $\mathbf{r}$ & $\mathbf{p}$ & $\mathbf{r}$ & $\mathbf{p}$ \\
\hline ANB angle (degree) & $0.139^{\dagger}$ & 0.266 & $0.491^{\dagger}$ & $<0.01 * *$ & $0.498^{\dagger}$ & $<0.01 * *$ \\
\hline Wits appraisal (mm) & 0.039 & 0.756 & $0.278^{\dagger}$ & $<0.05^{*}$ & $0.397^{\dagger}$ & $<0.01 * *$ \\
\hline Beta angle (degree) & $-0.126^{\dagger}$ & 0.312 & -0.078 & 0.532 & $-0.315^{\dagger}$ & $<0.01 * *$ \\
\hline AB plane angle (degree) & $-0.188^{\dagger}$ & 0.131 & $-0.304^{\dagger}$ & $<0.05^{*}$ & $-0.429^{\dagger}$ & $<0.01 * *$ \\
\hline Downs angle of convexity (degree) & $0.163^{\dagger}$ & 0.192 & $0.514^{\dagger \dagger}$ & $<0.01 * *$ & $0.533^{\dagger \dagger}$ & $<0.01 * *$ \\
\hline $\mathrm{W}$ angle (degree) & $0.187^{\dagger}$ & 0.132 & $0.231^{\dagger}$ & 0.062 & $-0.490^{\dagger}$ & $<0.01 * *$ \\
\hline
\end{tabular}

$\mathrm{N}=198$; Spearman's Correlation; correlation $=\mathrm{r}$

${ }^{\dagger}$ Weak Correlation $( \pm 0.01<r< \pm 0.5) ;{ }^{\dagger \dagger}$ Moderate Correlation $( \pm 0.5<r< \pm 0.8) ;{ }^{\dagger \dagger}$ Strong Correlation $( \pm 0.8<r< \pm 1)$

$* \mathrm{p}<0.05 ; * * \mathrm{p}<0.01$

Correlation between skeletal analyses and the soft tissue parameter was also determined for each sagittal class. Amongst the sagittal groups, no significant correlation was present in Class I sagittal groups. Downs angle of convexity showed a moderate positive correlation in Class II ( $\mathrm{r}=$ $0.514, \mathrm{p}<0.01)$ and Class III $(\mathrm{r}=0.533, \mathrm{p}<0.01)$ sagittal groups with the soft tissue angle of convexity (Table 5).

\section{DISCUSSION}

To achieve adequate esthetics, assessment of facial soft tissues is mandatory, so that the treatment goals may be oriented towards improving facial appearance ${ }^{17}$. As the skeletal structure forms the backbone of the overlying facial soft tissues, therefore their significance cannot be denied. Hence, the current study aimed to determine the skeletal parameter that correlates best with the soft tissue angle of convexity. This may concise the orthodontic diagnosis to minimal analyses based on the overlying facial soft tissues.

Facial soft tissues can be assessed by multiple methods. Previously, anthropometry and photographs were used as the diagnostic aids. With the advent of lateral cephalometry, soft tissue analysis became more precise as the soft tissue thickness and their relationship to the underlying skeletal structure can be accurately determined. A multitude of cephalometric methods have been described in literature for the evaluation of facial soft tissues. In addition to the analysis of individual structures such as the lip and nose, measurements describing the facial profile have also been proposed. These include jaw profile field, $\mathrm{H}$-line and the soft tissue angle of convexity ${ }^{22-26}$. There are many variations of 
soft tissue angle of convexity described in the literature ${ }^{28-31}$. The variant of soft tissue angle of convexity utilizing the glabella $\left(G^{\prime}\right)$ is said to remain stable with age, as this is minimally affected by soft tissue growth ${ }^{29-31}$. Hence, this parameter was used to evaluate the soft tissue profile in the current study.

In the current study, the sample was divided into Class I, Class II and Class III groups on the basis of soft tissue angle of convexity. The comparison of various skeletal parameters showed no statistically significant difference between males and females in different skeletal parameters. This is in concordance with another study conducted by Susilowati ${ }^{20}$.

Multiple studies have reported the correlation between various skeletal analyses ${ }^{18,19}$. In contrast, only few studies have reported the correlation between the sagittal skeletal analyses and soft tissue angle of convexity ${ }^{19,20}$. In our study, since no significant difference was present between males and females, the subjects were not stratified on the basis of gender. Downs angle of convexity showed a strong positive correlation with the soft tissue parameter. Susilowati ${ }^{20}$ in his study correlated Downs angle of convexity and soft tissue angle of convexity. He reported a moderate positive correlation between the Down's angle of convexity and the soft tissue angle of convexity in males and females. The variations in results might be due to differences in ethnicity, sample size, and exclusion of gender-based stratification in our study.

Correlation was also determined for each sagittal class separately. In our study, no statistically significant correlation was present between skeletal and soft tissue angle of convexity in Class I subjects. A moderate positive correlation was present between Downs angle of convexity and the soft tissue angle of convexity in Class II and Class III groups. Our results are in concordance with another study conducted by Raman et al. ${ }^{19}$.

It is worth mentioning here that the aforementioned studies correlated only Downs angle of convexity with the soft tissue parameter, where as in our study we correlated a total of six parameters with the soft tissue angle of convexity to validate their diagnostic accuracy in assessing the facial soft tissue profile.

\section{CONCLUSION}

All the sagittal skeletal analyses used in this study showed a significant correlation to the soft tissue angle of convexity. However, based on the higher values of correlation, ANB angle and Downs angle of convexity may be preferred to assess the sagittal skeletal pattern of an individual in soft tissue based diagnosis and treatment planning. This may facilitate the diagnosis and treatment of different sagittal malocclusion with a soft tissue oriented approach.

\section{ACKNOLEDGEMENT}

The authors would like to thank Dr. Waqar Jeelani (Assistant Professor and Head of Department, University Medical and Dental College, Faisalabad) for his assistance in statistical analysis.

\section{REFERENCES}

1. Jefferson Y. Facial Beauty-establishing a universal standard. Int J Orthod 2004; 15: 9-21.

2. Farhad B. Naini FB, Moss JP, Gill DS. The enigma of facial beauty: Esthetics, proportions, deformity and controversy. Am J Orthod Dentofacial Orthop 2006; 130: 277-82.

3. Broadbent H. A new x-ray technique and its application to orthodontia. Angle Orthod 1931; 1: 45-66.

4. Ackerman JL. Orthodontics: art, science or transcience? Angle Orthod 1974; 44: 243-50.

5. Jeelani W, Fida M, Shaikh A. Facial soft tissue thickness among three skeletal classes in adult Pakistani subjects. J Forensic Sci [Internet] 2015 Aug 11 [cited 2015 Sep 11]. Available from: http: //onlinelibrary.wiley.com/journal/10.1111/(ISSN)15564029/ early view [Epub ahead of print].

6. Arnett GW, Bergman RT. Facial keys to orthodontic diagnosis and treatment planning: Part I. Am J Orthod Dentofacial Orthop 1993; 103: 299-312.

7. Ackerman JL, Proffit WR, Sarver DM. The emerging soft tissue paradigm in orthodontic diagnosis and treatment planning. Clin Orthod Res 1999; 2: 49-52.

8. Downs WB. Variations in facial relationships: their significance in treatment and prognosis. Am J Orthod 1948; 34: 812-40.

9. Riedel RA. The relation of maxillary structures to cranium in malocclusion and in normal occlusion. Angle Orthod 1952; 22: 142-5.

10. Steiner CC. Cephalometrics for you and me. Am J Orthod 1953 Oct; 39: 720-55.

11. Freeman RS. Adjusting ANB angles to reflect the effect of maxillary position. Angle Orthod 1981; 51: 162-71.

12. Jacobson A. The Wits appraisal of jaw disharmony. Am J Orthod 1975; 67: 125-38. 
13. Haynes S, Chau MNY. The reproducibility and repeatability of the Wits analysis. Am J Orthod Dentofacial Orthop 1995; 107: 640-7.

14. Baik CY, Ververidou M. A new approach of assessing sagittal discrepancies: The Beta angle. Am J Orthod Dentofacial Orthop 2004; 126: 100-5.

15. Bhad WA, Subash N, Umal HD. A new approach of assessing sagittal dysplasia: The $\mathrm{W}$ angle. Eur J Orthod 2013; 35: 66-70.

16. Kavitha L, Karthik K. Comparison of cephalometric norms of Caucasians and non-caucasians: a forensic aid in ethnic determination. J Forensic Dent Sci 2012; 4: 53-5.

17. Ackerman JL, Proffit WR. Soft tissue limitations in orthodontics: treatment planning guidelines. Angle Orthod 1997; 67: 327-36.

18. Gul-e-Erum, Fida M. A comparison of cephalometric analyses for assessing sagittal jaw relationship. J Coll Physicians Surg Pak 2008; 18: 679-83.

19. Raman A, Shashikala KV, Padmini MN. Skeletal malocclusion and soft tissue angle of convexity: Do soft tissues camouflage underlying skeletal malocclusion? J Orofacial Health Sci 2011; 2: 6-11.

20. Susilowati. Correlation between soft tissue and skeletal profile of Deutero-malay Indonesians. Pak Orthod J 2009; 1: 40-3.

21. Subtelny JD. A longitudinal study of soft tissue facial structures and their profile characteristics, defined in relation to underlying skeletal structures. Am J Orthod 1959; 45: 481-507.
22. Burstone CJ. Lip posture and its significance in treatment planning. Am J Orthod 1967; 53: 262-84.

23. Holdaway RA. A soft-tissue cephalometric analysis and its use in orthodontic treatment planning: Part II. Am J Orthod 1984; 85: 279-93.

24. Subtelny JD, Rochester NY. A longitudinal study of soft tissue facial structures and their profile characteristics defined in relation to underlying skeletal structures. Am J Orthod 1959; 45: 481-507.

25. Muzj E. Biometric correlations among organs of the facial profile. Am J Orthod 1956; 42 : 827-57.

26. Burstone CJ. The integumental profile. Am J Orthod 1958; 44: 1- 25.

27. Pelton WJ, Elsasser WA. Studies of dentofacial morphology. IV. Profile changes among 6829 white individuals according to age and sex. Angle Orthod 1955; 25: 199- 207.

28. Bishara SE, Hession TJ, Peterson LC. Longitudinal softtissue profile changes: a study of three analyses. Am J Orthod 1985; 88: 209-23.

29. Bishara SE, Jakobsen JR, Hession TJ, Treder JE. Soft tissue profile changes from 5 to 45 years of age. Am J Orthod Dentofacial Orthop 1998; 114: 698-706.

30. Sharma P, Arora A, Valiathan A. Age changes of jaws and soft tissue profile. The Scientific World Journal 2014 Nov 20. doi: 10.1155/2014/301501

31. Obaidi HA, Abdul-Qadir MY. Facial soft tissue convexity changes. Al-Rafidain Dent J 2007; 7: 88-95. 